\title{
Streptokinase induced defibrination assessed by thrombin time: effects on residual coronary stenosis and left ventricular ejection fraction
}

Department of
Cardiology, Newham
General Hospital,
London
K Ranjadayalan
V Umachandran
Department of
Haematology, The
Royal London
Hospital, London
D Syndercombe-Court
C N Gutteridge
Department of
Cardiology, The
London Chest
Hospital, London
R Stevenson
B Marchant
S W Davies
A D Timmis
Correspondence to
Dr Adam D Timmis,
Department of Cardiology,
The London Chest Hospital,
Bonner Road, London
E2 9JX
Accepted for publication
13 February 1992

Cepartment of General Hospital, London

ematology, The

D Syndercombe-Cour

C N Gutteridge

Hospital, London

R Stevenson

Correspondence to

Dr Adam D Timmis,

The London Chest Hospital

E2 9JX

13 February 1992

Kulasegaram Ranjadayalan, Robert Stevenson, Bradley Marchant, Velaitham Umachandran, Simon W Davies, Denise Syndercombe-Court, Charles N Gutteridge, Adam D Timmis

\begin{abstract}
Objective-To evaluate laboratory markers of defibrination early after thrombolytic therapy and to determine their relation to residual stenosis and left ventricular ejection fraction measured angiographically before discharge from hospital.

Design-Prospective analysis of defibrination after streptokinase measured by fibrinogen assay and thrombin time to provide a comparison of these coagulation variables for predicting angiographic responses to treatment in patients with acute myocardial infarction.
\end{abstract}

Setting-The coronary care unit of a district general hospital.

Patients-44 patients with acute myocardial infarction treated by streptokinase infusion, all of whom underwent paired blood sampling before and one hour after streptokinase and cardiac catheterisation at a median of six (interquartile range 3-9) days later.

Main outcome measures-Assay of thrombin time and plasma fibrinogen concentrations one hour after streptokinase infusion. Relations between these coagulation variables and residual stenosis in the infarct related coronary artery and left ventricular ejection fraction. Separate analyses are presented for all patients $(n=44)$ and those with patency of the infarct related artery $(\mathbf{n}=35)$.

Results-Streptokinase infusion produced profound defibrination in every patient as shown by changes in thrombin time and circulating fibrinogen. Thrombin time after streptokinase infusion correlated significantly with both residual stenosis $(r=-0.43, p<0.005)$ and left ventricular ejection fraction $(r=0.38, p<0.02)$. The importance of these correlations was emphasised by the interquartile group comparison which showed that a thrombin time $\geqslant 49$ seconds predicted a residual stenosis of $74 \%$ and an ejection fraction of $65 \%$, compared with $90 \%$ and $49 \%$ for a thrombin time $\leqslant 31$ seconds $(p<0.01)$. When the analysis was restricted to patients with patency of the infarct related artery, the correlation between thrombin time and residual stenosis remained significant and group comparisons continued to show that patients in the highest quartile range had more widely patent arteries and better preservation of ejection fraction. Analysis of the fibrinogen data, on the other hand, showed insignificant or only marginally significant correlations with these angiographic variables.

Conclusions-Early after streptokinase infusion for acute myocardial infarction, the level of defibrination measured by thrombin time has an important influence on residual coronary stenosis and left ventricular ejection fraction at discharge from hospital, values above 49 seconds being associated with the best angiographic result.

\section{(Br Heart J 1992;68:171-5)}

Reduction in circulating fibrinogen has been regarded as a major requirement for successful thrombolytic therapy and some, ${ }^{2}$ though not all, ${ }^{3}$ investigators have confirmed that high residual plasma concentrations are often associated with non-patency of the infarct related coronary artery. Non-patency of the infarct related coronary artery at discharge from hospital has an adverse effect on one year mortality, ${ }^{4}$ and there is an empirical but unproved assumption that a high grade residual stenosis may also increase the risk of recurrent events. Left ventricular ejection fraction at discharge from hospital is recognised as an important determinant of long term outcome, ${ }^{56}$ but it remains unknown to what extent these angiographic variables are affected by the level of defibrination after thrombolytic therapy. The purpose of our study, therefore, was to evaluate laboratory markers of defibrination early after thrombolytic therapy and to determine their relation to residual stenosis and left ventricular ejection fraction found before discharge from hospital. Defibrination was estimated by fibrinogen assay and also by thrombin time (a measure of the functional integrity of circulating fibrinogen) to provide a comparison of these coagulation variables for predicting angiographic responses to infusion of streptokinase. ${ }^{7}$ 


\section{Patients and methods}

\section{PATIENTS}

Table 1 shows demographic data of the patients. We studied 44 patients with acute myocardial infarction treated with $1.5 \mathrm{mU}$ of streptokinase infused intravenously over one hour. Two hours after completion of streptokinase, the patients were anticoagulated with heparin infused at 1000 units/hour for 48 hours and thereafter were started on $75 \mathrm{mg}$ of aspirin daily according to treatment policy at the time this study was undertaken.

\section{BLOOD SAMPLING AND ANALYSIS}

Paired venous blood samples were taken immediately before streptokinase infusion and again one hour afterwards, before infusion of heparin had been started. Samples were drawn without venous occlusion, anticoagulated in sodium citrate, centrifuged, and the plasma frozen to $-20^{\circ} \mathrm{C}$ within 30 minutes of drawing the blood. The plasma was thereafter stored at $-80^{\circ} \mathrm{C}$ until analysis in one batch for measurement of fibrinogen concentration and thrombin time. Fibrinogen was measured by the method of Clauss ${ }^{8}$ and thrombin time by automated photodensitometry in an ACL-2000.

\section{CARDIAC CATHETERISATION}

All patients gave written informed consent for cardiac catheterisation by either Judkins or Sones techniques involving coronary arteriography with at least five views of the left system and three of the right, and single plane (right anterior oblique) left ventriculography. Studies were performed at a median of six (interquartile range 3-9) days after hospital admission to determine the patency of the infarct related coronary artery, the degree of residual stenosis, and left ventricular function. The infarct related artery was identified as the artery subtending the ventriculographic dyskinetic segment that corresponded to the area of acute injury on the admission electrocardiogram. In this study we encountered no ambiguity between circumflex and right coronary arteries in patients with inferior infarction. The coronary lesions were analysed for patency by two experienced

Table 1 Patient characteristics

\begin{tabular}{|c|c|c|}
\hline Characteristic & No & \\
\hline No of patients & 44 & \\
\hline $\begin{array}{l}\text { Age (median (interquartile range)) (y) } \\
\text { Sex }\end{array}$ & 59 & $(52-65)$ \\
\hline Men & 36 & \\
\hline Women & 8 & \\
\hline Infarct location & & \\
\hline Anterior & 22 & \\
\hline Inferior & 22 & \\
\hline History of previous infarction & 5 & \\
\hline $\begin{array}{l}\text { Time to streptokinase } \\
\text { (median (interquartile range)) (min) }\end{array}$ & 210 & $(155-278)$ \\
\hline $\begin{array}{l}\text { Time to cardiac catheterisation } \\
\text { (median (interquartile range)) (days) }\end{array}$ & 6 & $(3-9)$ \\
\hline Infarct related coronary artery & & \\
\hline Patent & 35 & \\
\hline Non-patent & 9 & \\
\hline Coronary artery disease & & \\
\hline Single vessel & 18 & \\
\hline Multivessel & 26 & \\
\hline $\begin{array}{l}\text { Left ventricular ejection fraction } \\
\text { (median (interquartile range)) }(\%)\end{array}$ & 58 & $(50-62)$ \\
\hline
\end{tabular}

observers (ADT, RS), the quantitative analysis being performed by RS alone. Both observers were blinded to the results of the coagulation analysis. For quantitative analysis, two views were selected that were most nearly orthogonal to the diseased segment and to one another with the least overlap of other coronary branches. The two views were projected with magnification onto white paper and traced by hand. Patency of the infarct related coronary artery was assessed by the thrombolysis in myocardial infarction (TIMI) criteria. ${ }^{9}$ Residual stenosis was taken at the narrowest point within the lesion related to the calibre of the normal segment immediately proximal to the lesion. The interobserver reproducibility of this technique has previously been reported. ${ }^{10}$ Left ventricular ejection fraction was measured by the method of Sandler and Dodge. ${ }^{11}$

\section{STATISTICAL ANALYSIS}

In all analyses, non-parametric statistics were used. Averaged values are expressed as median with the interquartile range in parentheses. Unpaired comparisons were made with the Mann-Whitney U test, paired comparisons with the Wilcoxon test, and correlations were examined with the Spearman rank correlation coefficient. Statistical significance was taken as $p \leqslant 0.05$ although marginal values $(>0.05-<0.1)$ have been recorded in the manuscript.

\section{Results}

RESPONSES TO STREPTOKINASE

Streptokinase infusion produced profound defibrination in every patient as reflected by reductions in circulating fibrinogen and increases in thrombin time. Bleeding complications occurred in two patients, one of whom suffered gastrointestinal haemorrhage requiring blood transfusion and the other frank haematuria. In both cases the baseline fibrinogen concentrations were high ( $3 \cdot 7$ and $4.0 \mathrm{~g} / \mathrm{l})$ compared with the remainder of the group, and showed an exaggerated decline $(-3.6$ and $-3.9 \mathrm{~g} / \mathrm{l})$ in response to streptokinase. Table 2 shows responses to streptokinase.

\section{DEFIBRINATION AND CORONARY PATENCY}

Coronary arteriography after three to nine days showed patency of the infarct related artery in 35 cases $(80 \%)$. Comparison of coagulation variables in patients with and without coronary artery patency showed no significant differences. Quantitative analysis, however, of the degree of residual stenosis (range 39\%-100\%) showed a highly significant correlation with the thrombin time one hour after streptokinase. When analysis was confined to the 35 patients with patency of the infarct related artery, the correlation between residual stenosis (range $39 \%-99 \%$ ) and thrombin time remained statistically significant. Correlations with circulating fibrinogen, on the other hand, were not significant.

The relation between defibrination and the efficacy of treatment is emphasised in figures 1 and 2 where residual stenoses of patients in the 
Table 2 Coagulation variables before and one hour after streptokinase infusion

\begin{tabular}{lrlll}
\hline & $\begin{array}{l}\text { Before streptokinase } \\
\text { (median (interquartile range)) }\end{array}$ & $\begin{array}{l}\text { 1 hour after streptokinase } \\
\text { (median (interquartile range)) }\end{array}$ & p Value \\
\hline Fibrinogen $(\mathrm{g} / \mathrm{l})$ & $2 \cdot 8$ & $(2 \cdot 3-3 \cdot 3)$ & $0 \cdot 21(0 \cdot 16-0 \cdot 27)$ & $<0.001$ \\
Thrombin time $(\mathrm{s})$ & 13.7 & $(11 \cdot 6-15 \cdot 7)$ & $37 \cdot 1 \quad(30 \cdot 7-48 \cdot 9)$ & $<0.001$ \\
\hline
\end{tabular}

Figure 1 The effects of thrombin time and plasma fibrinogen one hour after streptokinase on residual coronary stenosis and left ventricular ejection fraction ( $L V E F)$. These data are for all of the 44 patients and compare the highest $(n=11)$ and lowest ( $n=11)$ quartile ranges for each coagulation variable. Each box plot displays the 10th, 25th, 50th, 75th and 90th

percentile values. Notches represent $95 \%$ confidence intervals about the median.

Figure 2 The effects of thrombin time and plasma fibrinogen one hour after streptokinase on residual coronary stenosis and left ventricular ejection fraction (LVEF). These data are for the 35 patients with patency of the infarct related artery and compare the highest $(n=9)$ and lowest $(n=9)$ quartile ranges for each coagulation variable. Each box plot displays the 10th, 25th 50th, 75th and 90th percentile values. Notches represent $95 \%$ confidence intervals about the median.

highest and lowest quartile ranges for thrombin time and fibrinogen are compared. Patients in the highest quartile range for thrombin time had more widely patent arteries with significantly less severe residual stenoses than patients in the lowest quartile range, regardless of whether the analysis included all patients (fig 1) or only those with a patent infarct related artery (fig 2). Fibrinogen analysis, on the other hand, was less helpful and failed to separate patients on the basis of residual stenosis.
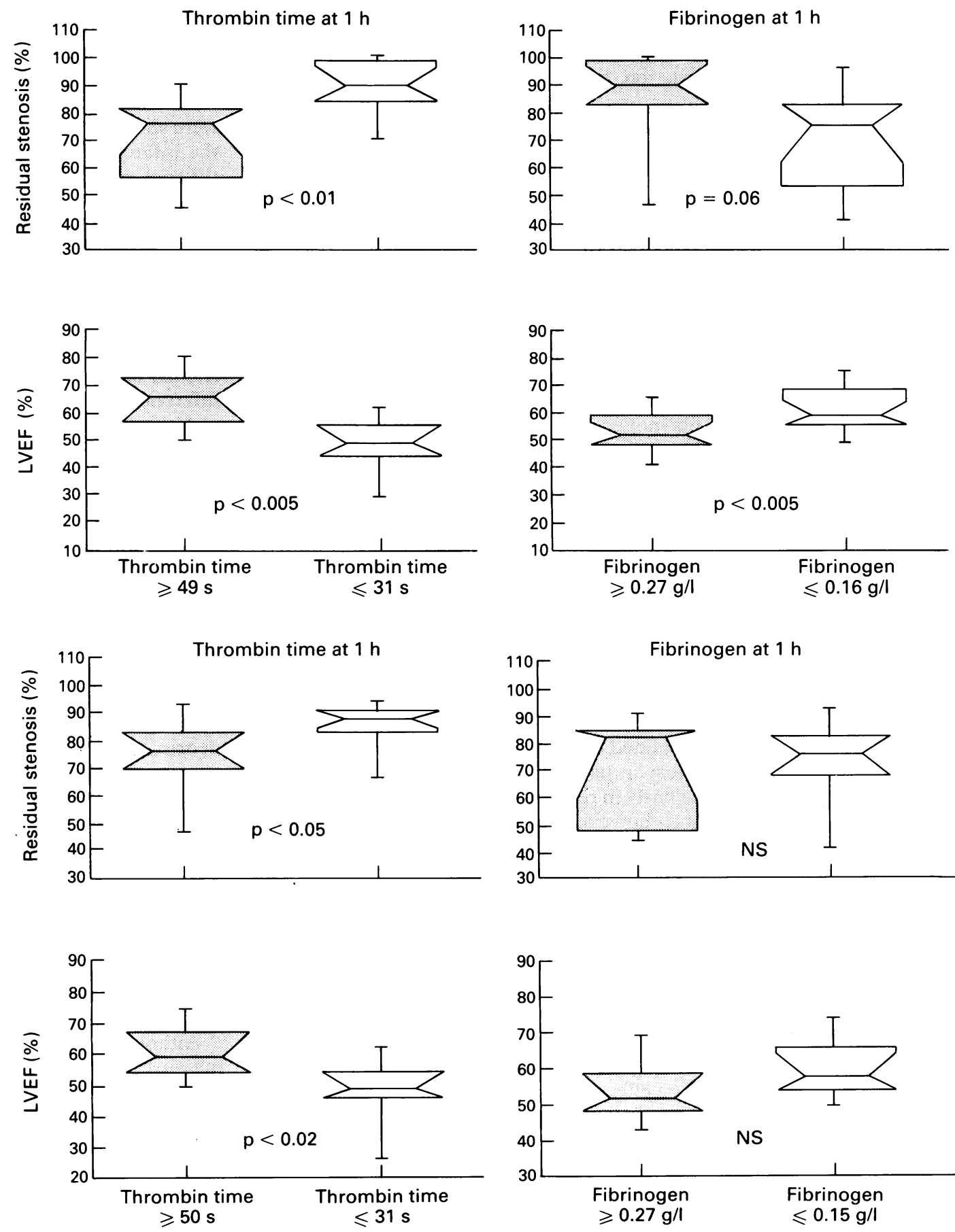
the analysis was confined to patients with a patent infarct related artery the correlation was weaker and just failed to reach statistical significance (table 3). Nevertheless, the interquartile group comparisons confirmed that patients in the highest range for thrombin time had significantly better preservation of left ventricular ejection fraction than patients in the lowest range, regardless of whether all patients were included or only those with a patent infarct related artery (figs 1 and 2).

DEFIBRINATION AND LEFT VENTRICULAR EJECTION FRACTION

Defibrination after streptokinase was an important determinant of residual left ventricular ejection fraction shortly before discharge from hospital. Thus the thrombin time one hour after treatment correlated significantly with left ventricular ejection fraction, although when 
Table 3 Relation between coagulation variables, residual coronary stenosis, and left ventricular ejection fraction

\begin{tabular}{|c|c|c|c|c|}
\hline & \multicolumn{4}{|c|}{ Coagulation variable 1 hour after streptokinase } \\
\hline & \multicolumn{2}{|c|}{ Thrombin time (s) } & \multicolumn{2}{|c|}{ Fibrinogen $(g / l)$} \\
\hline & $r^{\star}$ & p Value & $r^{\star}$ & p Value \\
\hline $\begin{array}{l}\text { All patients }(\mathrm{n}=44) \text { : } \\
\text { Residual stenosis }(\%) \\
\operatorname{LVEF}(\%)\end{array}$ & $\begin{array}{r}-0.43 \\
0.38\end{array}$ & $\begin{array}{l}<0.005 \\
<0.02\end{array}$ & $\begin{array}{r}0.28 \\
-0.29\end{array}$ & $\begin{array}{l}0.07 \\
0.05\end{array}$ \\
\hline $\begin{array}{l}\text { Patients with patent IRCA }(\mathrm{n}=35) \text { : } \\
\text { Residual stenosis }(\%) \\
\operatorname{LVEF}(\%)\end{array}$ & $\begin{array}{r}-0.38 \\
0.32\end{array}$ & $\begin{array}{r}<0.05 \\
0.06\end{array}$ & - & $\begin{array}{l}\text { NS } \\
\text { NS }\end{array}$ \\
\hline
\end{tabular}

*Correlation coefficient (Spearman's rank method). IRCA, infarct related coronary artery.

Plasma fibrinogen concentrations one hour after streptokinase also correlated weakly with left ventricular ejection fraction when data for all patients were analysed. The interquartile group comparison confirmed that patients in the lowest range for fibrinogen concentration had significantly better preservation of ejection fraction (fig 1). When the analysis was confined to patients with a patent infarct related artery neither the correlation with ejection fraction nor the interquartile group comparison was significant.

\section{Discussion}

High plasma fibrinogen concentrations after thrombolytic therapy are often associated with non-patency of the infarct related coronary artery. ${ }^{12}$ In our study, however, this association could not be tested because all the patients showed profound reductions in circulating fibrinogen that exceeded $80 \%$ in every case. Nevertheless, quantitative analysis of residual coronary stenosis showed that the degree of arterial patency correlated significantly with the level of defibrination when this was assessed by measurement of thrombin time. The importance of this correlation was emphasised by the interquartile group comparison which showed that a thrombin time of more than 49 seconds after streptokinase was associated with a median residual stenosis of $74 \%$, compared with $90 \%$ for a thrombin time of less than 31 seconds. Part of this difference might be explained by non-patency of the infarct related artery in patients who did not defibrinate sufficiently in response to streptokinase. This does not, however, provide the full explanation because the difference, though more weakly significant, persisted even when patients with non-patency were excluded from analysis indicating that the association between high grade residual stenosis and attenuation of the thrombin time response was not merely the result of failed thrombolysis. The data suggest, therefore, that vigorous defibrination early after streptokinase, as indicated by significant prolongation of the thrombin time, ensures more effective thrombolysis and a more widely patent infarct related artery.

Arterial patency is a major goal of thrombolytic therapy that may have an important independent influence on long term prognosis. ${ }^{4}$ The degree of arterial patency, however, as reflected by residual stenosis, has received less attention as a predictor of outcome although, in interventional studies, patients treated by direct angioplasty have been shown to have more widely patent arteries and better preservation of ventricular function than those treated by intracoronary streptokinase. ${ }^{12}$ The findings in our study are to some extent analogous, in that an exaggerated thrombin time response was associated not only with a more widely patent coronary artery but also with better preservation of left ventricular ejection fraction. Although correlations between thrombin time and left ventricular ejection fraction were generally weak, and just failed to reach statistical significance, in the subgroup with coronary patency interquartile group comparison with data on thrombin time showed highly significant differences between residual ejection fractions for patients in the highest and lowest quartile ranges. Thus a thrombin time of more than 49 seconds was associated with a median ejection fraction of $65 \%$ compared with only $49 \%$ for a thrombin time of less than 31 seconds. Similar differences were shown when patients with non-patency of the infarct related artery were excluded from the analysis, again indicating that these findings were not merely a reflection of the known association between failed thrombolytic therapy and more extensive myocardial injury. Thus the data suggest that the level of defibrination, as shown by the thrombin time one hour after streptokinase infusion, may have an important influence on the residual left ventricular ejection fraction after acute myocardial infarction.

Although mechanisms relating defibrination to ejection fraction are not clear, the degree of arterial patency may play a contributory part. Thus vigorous defibrination produces a more widely patent infarct related artery that may permit more effective and perhaps earlier reperfusion leading to greater myocardial salvage. A less vigorous response, on the other hand, associated with high grade residual stenosis, is unlikely to restore adequate perfusion, particularly after thrombolytic therapy when the dynamics of coronary flow are adversely affected by plaque rupture and intraluminal thrombotic debris. ${ }^{10}$ Nevertheless, residual stenosis and ejection fraction were not significantly correlated in our study indicating that other factors may also play a part in the association between defibrination and left ventricular function. Recent experimental data suggest that thrombolytic therapy may reduce infarct size independently of reperfusion and, ${ }^{1314}$ if the same applies clinically, defibrination may influence myocardial salvage directly; although whether this contributed to the findings in our study remains speculative.

Although the level of defibrination as measured by thrombin time correlated with residual stenosis and left ventricular ejection fraction, plasma fibrinogen itself correlated only weakly with these variables, and not at all when patients with non-patency of the infarct related artery were excluded from the analysis. This may reflect the relative inaccuracy of the 
Clauss method, ${ }^{8}$ which, although widely used for assessment of fibrinogen responses to thrombolytic therapy, ${ }^{1-3}$ may give falsely low values if fibrin degradation products are present. Indeed, there has been some inconsistency about the value of fibrinogen assay by this method for assessing responses to thrombolytic therapy and at least one group of investigators has reported no relation with coronary patency. ${ }^{3}$ It is perhaps not surprising, therefore, that when defibrination was measured by plasma fibrinogen, it failed to correlate with residual stenosis because this would demand of the assay a level of accuracy beyond that required for an all or none prediction of patency. Thrombin time, on the other hand, measures the functional integrity of circulating fibrinogen and is not affected by fibrin degradation products. Probably for this reason it provided a better test of the thrombolytic efficacy of streptokinase in our study.

It was our specific purpose to evaluate laboratory measurements of defibrination early after thrombolytic therapy for predicting coronary patency and left ventricular fraction at discharge from hospital when decisions about further management are usually made. Thus angiography was delayed from three to nine days when recovery from the acute phase of infarction was complete. Even at this fairly late stage, however, reversible myocardial stunning continues to make a variable contribution to alterations in ejection fraction. ${ }^{15}$ Moreover, any time delay between treatment and angiography is associated with continued remodelling of the lesion within the infarct related artery, driven partly by the ongoing lytic effects of treatment, and partly by endogenous mechanisms. ${ }^{10}$ Taken together these factors may have blunted the predictive value of our measurements by weakening correlations between defibrination and the angiographic data. Indeed, the fact that thrombin time one hour after streptokinase infusion remained significantly related to both residual stenosis and ejection fraction about a week later confirms the potential value of this test for monitoring responses to treatment.

The potential benefits of exaggerated defibrination must be set against the risk of bleeding, which affected two patients in our study. Fibrinogen degradation products have complex adverse effects on haemostasis, ${ }^{16}$ and it is noteworthy that both patients with bleeding complications had high baseline fibrinogen concentrations that declined by $96 \%$ in response to streptokinase infusion. This may well have contributed towards their tendency to haemorrhage although in general the magnitude of systemic defibrination and its laboratory derangements have not been shown to correlate with bleeding. ${ }^{1718}$ Thus neither patient who bled had prolongation of the thrombin time beyond 40 seconds indicating that this particular measure of defibrination may not help identify patients at risk.
The findings in this study may have implications for clinical practice. Thus whereas some previous investigators have found that fibrinogen depletion encourages coronary patency after thrombolytic therapy ${ }^{12}$ our study indicates that the more exaggerated the defibrination, the greater the coronary patency and the better the preservation of ventricular ejection fraction at the time of discharge from hospital. Simple measurement of thrombin time one hour after treatment seems particularly useful for assessing responses to treatment, values above 49 seconds being associated with the best angiographic results.

1 Lew AS, Cercek B, Hod H, Shah PK, Ganz W. Usefulness of residual plasma fibrinogen after intravenous streptokinase for predicting delay or failure of reperfusion in acute myocardial infarction. Am J Cardiol 1986;58:680-5.

2 Brügemann J, Van der Meer J, Takens BH, Hillege H, Lie KI. A systemic non-lytic state and local thrombolytic failure of anistreplase (anisoylated plasminogen streptokinase activator complex, APSAC) in acute myocardial infarction. Br Heart J 1990;64:355-8.

3 White CW, Schwartz JL, Ferguson DW, Brayden CW Kelly KJ, Kioschos JM, et al. Systemic markers of fibrinolysis after unsuccessful intracoronary streptokinas thrombolysis for acute myocardial infarction: does nonreperfusion indicate failure to achieve a systemic lytic state? Am J Cardiol 1984;54:712-7.

4 Kennedy JW, Ritchie JL, Davis KB, Stadius ML, Maynard $\mathrm{C}$, Fritz JK. The Western Washington randomized trial of intracoronary streptokinase in acute myocardial infarction: a 12 month follow-up report. $N$ Engl J Med 1985;312:1073-8.

5 Risk stratification and survival after myocardial infarction The Multicenter Postinfarction Research Group. N Engl J Med 1983;309:331-6.

6 Mukharji J, Rude RE, Poole WK, Gustafson N, Thomas LJ Strauss $\mathrm{HW}$, et al. Risk factors for sudden death after acute myocardial infarction; two-year follow-up. $\mathrm{Am} \mathrm{J}$ Cardiol 1984;54:31-6.

7 Shafer KE, Santoro SA, Sobel BE, Jaffe AS. Monitoring activity of fibrinolytic agents: a therapeutic challenge. $A m$ $J$ Med 1984;76:879-86.

8 Clauss A. Gerinnungsphysiologische Schnellmethode zur Bestimmung des Fibrinogens. Acta Haematol 1957;17:

9 Chesebro JH, Knatterud G, Roberts R, Borer J, Cohen LS Dalen J, et al. Thrombolysis in myocardial infarction (TIMI) trial, phase 1: a comparison between intravenous tissue plasminogen activator and intravenous streptokinase. Circulation 1987;76:142-54

10 Davies SW, Marchant B, Lyons JP, Timmis AD, Rothman MT, Layton CA, et al. Coronary lesion morphology in acute myocardial infarction: demonstration of early remodelling after streptokinase treatment. $J \mathrm{Am}$ Coll Cardiol 1990;16:1079-86.

11 Sandler H, Dodge HT. The use of single plane angiocardiograms for the calculation of left ventricular volume in man. Am Heart $J$ 1968;75:325-34.

12 O'Neill W, Timmis GC, Bourdillon PC, Lai P, Ganghadarhan $\mathrm{V}$, Walton Jr J, et al. A prospective randomized clinical trial of intracoronary streptokinase versus coronary angioplasty for acute myocardial infarction. $N$ Engl $J$ Med 1986;314:812-8.

13 Hochman JS, Choo $\mathrm{H}$. Limitation of myocardial infarct expansion by reperfusion independent of myocardial salvage. Circulation 1987;75:299-306.

14 Chakrabarty S, Flores NA, Sheridan DJ. Can thrombolytic treatment produce beneficial effects in the absence of coronary recanalisation during acute myocardial infarction? [abstract]. Br Heart J 1991;66:92.

15 Braunwald E, Kloner RA. The stunned myocardium: prolonged postischemic ventricular dysfunction. Circulation 1982;66:1146-9.

16 Arnold AER, Brower RW, Collen D, Gerrit-Anne Van ES Lubsen J, Serruys PW, et al. Increased serum levels of fibrinogen degradation products due to treatment with recombinant tissue-type plasminogen activator for acute myocardial infarction are related to bleeding complications, but not to coronary patency. J Am Coll Cardiol 1989;14:581-8.

17 Bell WR, Meek AG. Guidelines for the use of thrombolytic agents. N Engl J Med 1979;301:1266-70.

18 Sharma GVRK, Cella G, Parisi AF, Sasahara AA Thrombolytic therapy. $N$ Engl J Med 1982;306:1268-76. 